\title{
Determination of indoor air quality in collective living spaces utilizing Fuzzy logic analysis
}

Ahmet Çoşgun (Main and Corresponding Author)

Akdeniz University, Vocational School of Technical Sciences

Main Campus, Antalya (Turkey)

acoskun@akdeniz.edu.tr

https://orcid.org/0000-0002-0243-5476

Manuscript Code: 13778

Date of Acceptance/Reception: 20.11.2020/30.03.2020

DOI: 10.7764/RDLC.19.3.288

\begin{abstract}
Individuals collective living spaces might be indoor or outdoor areas. In indoor works, people spend approximately $90 \%$ of their time in a closed space. There are many parameters affecting indoor air quality. Among these, for indoor and outdoor, important parameters can be listed as carbon monoxide (CO), carbon dioxide $\left(\mathrm{CO}_{2}\right)$, sulfur dioxide $\left(\mathrm{SO}_{2}\right)$, particles, nitrogen oxides ( $\mathrm{NOx}$ ), various microorganisms, harmful allergens, and powders. These are important factors for occurring many acute and chronic diseases at an early age, as babies and children are more sensitive to environmental pollutants. Recently published studies, which report that appendicitis failures might be fatal and air pollution can increase the rate of these failures, are remarkable. There are many negative effects of polluted indoor air on human health such as attention deficit and excessive daytime sleepiness. Moreover, the negative effects of this kind of indoor air quality on human learning and perception can not be neglected. The researchers focusing on indoor air quality are conducting studies showing that air pollution has an effect on physical activity and neurological interaction in humans. Even though air pollutants in outdoor air content were evaluated with fuzzy logic method in many studies, there are quite few studies using the fuzzy approach for indoor air quality. In this study, through the standard formula developed by the United States Environmental Protection Agency (EPA), calculations were made using fuzzy logic in MATLAB utilizing air quality index. In this scope, indoor air quality measurement parameters were evaluated with the "Mamdani" method used in fuzzy logic. Then, the model suitable for the logic structure created with the fuzzy tool in MATLAB was analyzed with the help of Mamdani method, and the suitability of evaluating the indoor air quality with artificial intelligence was investigated. Finally, a set of suggestions has been made evaluating and criticizing the results.
\end{abstract}

Keywords: Public living space, Indoor air quality, $\mathrm{CO}_{2}, \mathrm{PM}_{10}$, Fuzzy Logic

Introduction

An indoor environment is an area constructed and isolated by human-made interventions. People spend $90 \%$ of their time in indoor environments and generally continue to work in these places. Many studies on indoor air have revealed that indoor air contains more levels of pollutants than outdoor air. Indoor air quality covers all non-heat-related points in the air that affect a person's physical and mental health. Since people have different perceptions of air, a precise limit and definition of indoor air quality cannot be made and, therefore, therefore the term, namely, "acceptable indoor air quality" has emerged (Bulut, 2012).

Indoor air quality is defined as the air condition in which the pollutants detected below the harmful level determined by the authorized institutions and $80 \%$ of the people in this air do not feel any discomfort regarding the quality of the air (Ashrae, 2007).

Indoor air exposure and its impacts on health are among the priority issues of the World Health Organization (WHO) (Oliviera et al. 2016). The main causes of indoor or outdoor air pollution are the appearance of substances which do not exist naturally in the air content and the increase in quantities of substances which are in a non-harmful amount in the air. The substances negatively affect the lives of people, plants, and animals, and cause physical damage and economic losses. Millions of people worldwide are exposed higher air concentration levels than safe standard amounts. Pollutants from traffic, transportation, heating, and industry are the main air pollutants. As a result of the uncontrolled consumption of fossil fuels in developing countries such as Turkey, sulfur dioxide and particulate matter (PM10) is the major portion of contaminants harmful to human health. Indoor and outdoor air quality remains a problem in the World (Caykaytar et al., 2013).

Pollutants added to the indoor air from many sources in public living spaces can cause acute and chronic health problems. A case in point for these chronic problems are newborns and infants. The immune systems of babies and children are less developed than adults. One of the most important reasons for this is that children are in the process 
of continuous growth and development. Accordingly, it has been shown in various studies that babies and children are more sensitive to environmental pollutants (Lakestani et al., 2017).

Indoor air refers to inhaled air in places such as houses, public buildings, schools, universities, hotels, theaters, cinemas, libraries, hospitals, shopping malls, vehicles, waiting rooms. The biological, physical and chemical components in this air can be listed as Carbon monoxide, Carbon, Sulfur dioxide, Azotoxides, various microorganisms and harmful allergens. If the level of any component changes to the level that disturbs the individuals, the air quality is completely deteriorated.

Polluted air conditions have many negative effects on human health, such as attention, messiness, and increased sleepiness. On the other hand, the negative effects on "learning" in education and training cannot be ignored. The amount of $\mathrm{CO}_{2}$ (carbon dioxide) in the classes during the summer and winter months when the education continues, is below 1000 ppm, which is accepted as a limit value of 62.1-2016, determined by ASHRAE (American Society of Heating Refrigerating and Air Conditioning Engineers) before the lesson. However, this limit is quickly exceeded within the first 10 minutes. This situation has negative effects on the success levels of the students and their learning abilities and requires managers to take necessary precautions on the subject (Kuşcu, 2018).

The management of internal environmental quality also includes control of thermal conditions and adequate ventilation.

Nine simulations were carried out in a school building in the Spanish climate zone D3 to change the time of the day and accordingly to close the blinds of the windows in the classrooms. When the classes in the school teach between 14:00 and 21:00 from October to May and between 7:00 and 14:00 in September, the energy savings are 50\% with the work done when the shutters are closed in the summer and winter evenings. determined. From here, it was found that the annual energy cost savings achieved over a year was $€ 6,120$. It turns out that optimum economical injections can be achieved in school buildings only with the changes in the amount of energy entering through the windows (radiation) (Gomez et al., 2019).

Controlling the thermal environment in schools and ensuring adequate ventilation can reduce symptoms and absence due to disease, as well as contribute to performance and learning. Low ventilation rate in buildings causes an increase in exposure in addition to its effect on human health and performance. Therefore, the control of pollutant sources should be the main strategy. Effective moisture control can prevent humidity and mold based problems and make a positive contribution to the respiratory health of the students. In recent studies, it has been shown that cleaning the surfaces with high contact frequency is associated with health problems, especially symptoms related to the digestive system (Shaughnessy, 2015).

Indoor air quality and comfort are studied intensively both in America (ASHRAE) and in Europe (EN Standards / REHVA). The main standards in the world can be listed as follows:

1- ASHRAE Standard 62-2004,

2- EN 15251

In standard 62, two methods are defined for achieving acceptable indoor air quality and they described as follows: a- Ventilation quantity method, b- Indoor air quality method (Oral \& Arısoy, 2015).

$\mathrm{CO}_{2}$ is an important indoor pollutant recommended to control indoor air quality. Normally, $0.03 \%$ of atmospheric air by volume is $\mathrm{CO}_{2} . \mathrm{CO}_{2}$ in outdoor air concentration varies between 330 and 500 ppm depending on the environmental characteristics. Therefore, it is not possible to exclude $\mathrm{CO}_{2}$ from the indoor environment. $\mathrm{CO}_{2}$ is not a poisonous gas, but it may pose a drowning due to lack of oxygen. When the concentration value exceeds 35000 ppm, central breath nerve receptors are triggered and it causes breathing deficiency. The central nervous system is unable to function due to the lack of oxygen at higher concentrations (Ashrae, 2003).

When carbon dioxide rises to high levels, it affects respiration and the respiratory rate increases. This situation causes the person doing work gets tired more and the job ability of the individual decreases. The effects of $\mathrm{CO}_{2} \mathrm{Concentration}$ in the air can be listed as follows:

- Nonhazardous for $1-3 \%$ concentration in medium-term exposure

- Headaches begin at 3-6\% concentration

- Dizziness, visual disturbances, and unconsciousness begins at $6 \%$ to $10 \%$ concentration

- Narcotic effects are seen in concentrations bigger than $10 \%$. 
The choking effect is caused by oxygen shortage rather than $\mathrm{CO}_{2}$ excess (Altın \& Taşdemir, 2018).

Studies are carried out by considering many measurements related to $\mathrm{CO}_{2}$. In recent years, on the estimated carbon footprint studies have been conducted in Turkey (Coskun \& Oktay, 2020). Moreover, there are also studies on the reduction of $\mathrm{CO}_{2}$ emissions in the electricity network in Turkey (Coskun, 2019). In these studies, parameter values in outdoor weather conditions have been considered and it is seen that there are original studies. Studies can be conducted on issues similar to these studies in terms of indoor air quality, especially considering the management system.

Particulate matter (PM), which is one of the pollutant parameters affecting the indoor air quality, is substances that can exist as solid or liquid in the air and its dimensions vary between 0.1 and $100 \mu$. The particles of which aerodynamic diameter below $10 \mu \mathrm{m}$ are called as PM10 and the ones of which aerodynamic diameter below $2.5 \mu \mathrm{m}$ are named as PM2.5 or fine particles. Also, particles in the range of 2.5-10 $\mu \mathrm{m}$ are called coarse particles. Particles can be classified into various groups such as bioaerosols containing powders, fumes, fog, viruses, bacteria, fungal spores and pollen, coarse, fine, visible or invisible ones (Tül \& Saraç, 2015).

The physical structure and chemical composition of the particles are very important for health. When the particulate matter rate is high, it reduces visibility, influences climate change and adversely affects human, animal and plant health. Especially, particulate substances containing cancer-causing organic chemicals (PAH, dioxin, furan, etc.) are very dangerous for human health. Such particles combine with moisture in the lungs and are converted into acid, slow down the conversion of carbon dioxide in the blood to oxygen by reaching the lung. In this case, since the heart needs to work harder to eliminate oxygen loss, it creates serious pressure on the heart (Knudsen \& Rasmussen, 2011).

The effects of indoor air quality on human health

\section{The effect of temperature on human health depending on indoor air quality}

In environments with low temperatures, the heart pumps more blood to maintain body temperature. As the ambient air temperature is lower than needed, the mucous in the respiratory tract (bronchus, sinus, etc.) is irritated and it leads to an increased likelihood of many diseases such as colds and flu. In environments with high temperatures, favorable conditions are created for the growth and spread of microorganisms that cause disease.

\section{The effect of relative humidity on human health depending on indoor air quality}

According to the thermal comfort conditions in German DIN 1946, temperatures can be in a range of $20-260{ }^{\circ} \mathrm{C}$ and relative humidity can vary in a range of $30 \%$ and $65 \%$. Absolute humidity value is limited to $11.5 \mathrm{~g} / \mathrm{kg}$ air. The relative humidity rate provided by HVAC systems is very effective for the comfort and health of people. Increasing the humidity in the public areas can cause condensation and mold formation on system components such as heater and cooler batteries, humidifier assembly, water collecting pan, grilles, air ducts, aspirators and ventilators and insulation products that are not cleaned and maintained. The relative humidity of the indoor air higher than $65 \%$ to $84 \%$ makes difficult to control the body temperature and negatively affect human health (Köksal, 2011). In the studies, it has been observed the number of skin and eye dryness complaints and sensitivity rates in relative humidity range varying in $30 \%$ to $40 \%$ levels are higher than that of the humidity rates in $20 \%$ to $30 \%$. However, the optimum relative humidity for the nose, throat, and lungs is $40 \%$. Appropriate relative humidity values for human health determined by ASHRAE are given in Figure 1.

The low level of relative humidity directly affecting the indoor air quality affects the eyes in individuals. In the eyes, $98 \%$ to $99 \%$ of the tear is known to be water and excessive evaporation occurs due to low humidity, causing poor visual quality. This situation brings about a feeling of stinging, burning, tiredness, tension and heaviness in the eyelids. In the later stages of the disease, inflammation and visual disturbances appear on the eye (Çilinfiroğlu, 2010). 


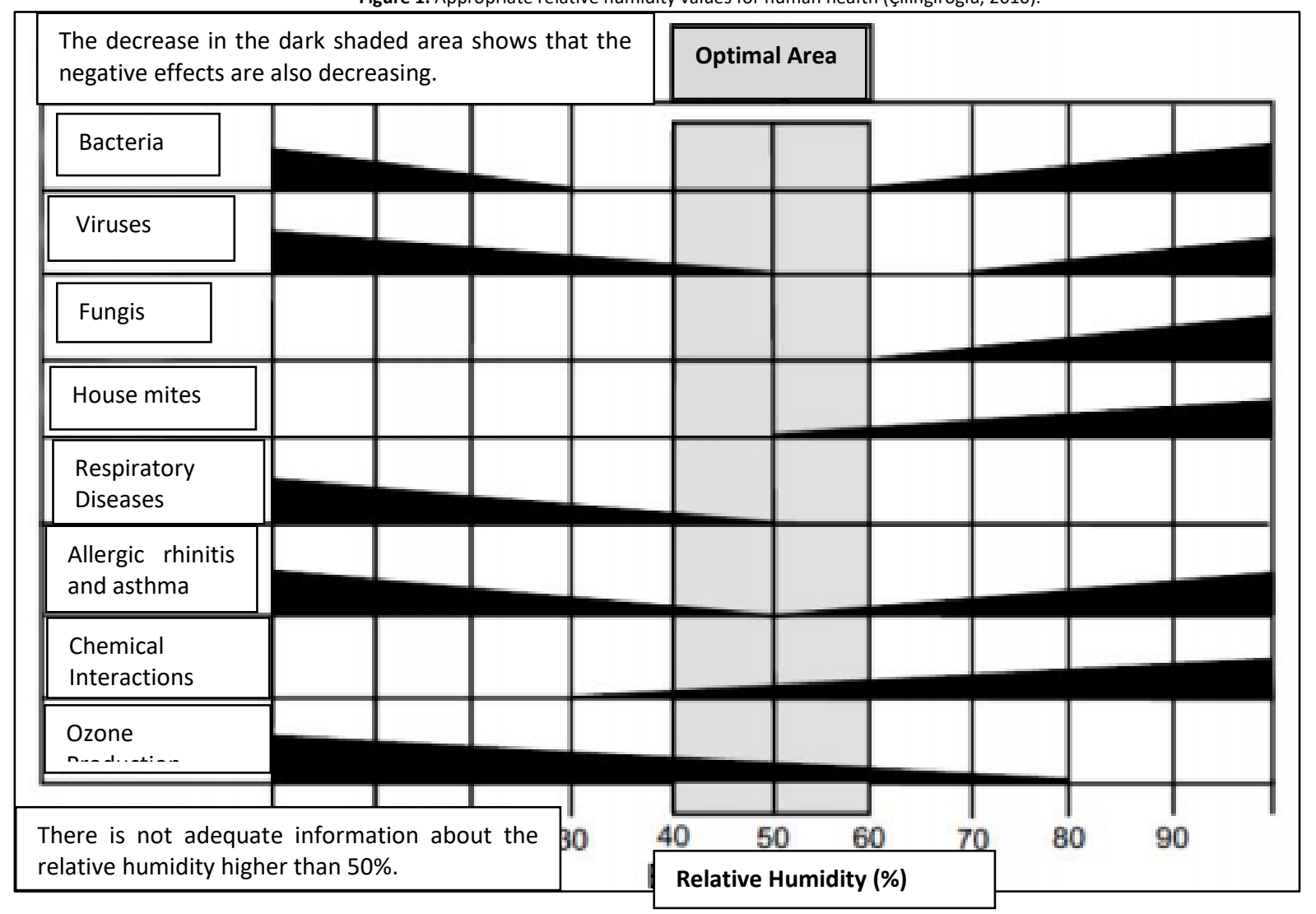

The effect of airflow rate on human health depending on indoor air quality

The measured value of air moving in a particular direction in unit time is called as "air velocity". Indoor air velocity is the arithmetic mean value of the velocity derived from many average air velocities measured locally within a specific region (Ceylan, 2011). The air velocity in an indoor environment has a significant effect on heat loss from the human body. Since the high airflow rate in the summer accelerates the evaporation of the water on the body surface in hot weather conditions, it is beneficial for the comfort of the person, but the high values in the winter create discomfort. Although the sensitivity of the airflow rate varies from person to person, airspeeds less than $0.1 \mathrm{~m} / \mathrm{s}$ are not perceived by people and the speeds greater than $0.2 \mathrm{~m} / \mathrm{s}$ bring about discomfort and unfavorable effects on the user in the rate of more than $20 \%$. The airflow rate required for an indoor environment varies according to the action intended, the regional climate characteristics, the status of pollutants, pollutant sources and the number of people in the environment (Eres, 2019).

In a study conducted in University of Calgary, the conditions of 35,811 patients who were hospitalized in 12 cities of Canada due to appendicitis were evaluated and the data of each city's daily maximum ozone concentration and air pollution were investigated It was observed that high ozone level was associated with an increase in the number of hospitalized patients due to appendicitis. It was highlighted, in this study, that every 16 PPB (one billionth of a particle) increase in ozone concentration led to an increase in appendicitis cases up to $22 \%$. It was reported in the study that appendicitis failures can be fatal and air pollution can accelerate it (Kaplan et al., 2013).

It has been pointed out that exposure of air pollution from traffic may have a negative effect on cognitive developments related to exercise. In this study, it has been emphasized that the exposure of air pollution on BDNF expression and secretion in the brain may include inflammatory, acute and negative effects. It was concluded that more research is needed to reveal the neurological effects of air pollution and possible interactions with physical activity, and to analyze the neurological effects of air pollution exposure during acute and regular exercise (Bos et al., 2014).

In addition to air pollution caused by heavy traffic and industry, carcinogenic dust particles that arise due to the demolition of old buildings in urban transformation increase the risk of mesothelioma and lung cancer. Asbestos is known as the most important cause of lung membrane cancer (malignant mesothelioma), and it is found locally (regionally) due to its frequent use of white soil where asbestos is concentrated. The structural elements based on terra 
alba, which are among the parameters affecting the indoor air quality and which are still used in Anatolian village houses, should be examined in terms of indoor air quality. It is estimated that the rate of lung membrane cancer (malignant mesothelioma) will increase within next 20 to 50 years. Employees working in demolition works of urban transformation in Turkey must be avoided from the exposure of dirty and dusty air and, the authorities must take serious measures during the demolition of old buildings under the urban renewal process. The indoor environment does not only imply the buildings but also isolated working places and, therefore operators in construction machines are also considered to work in an indoor environment during demolition works. It should be ensured that personnel, especially those working in demolition, are not exposed to dirty and dusty air. Care must be taken to ensure that destruction does not pollute the air as much as possible (Web site-1).

People need to do sports to stay healthy. However, considering the low number of open-air spaces to work out in the cities and the excessive working hours, people started to do sports in indoor environments such as gyms. While doing sports, the respiratory muscles work at maximum capacity, so it is known that the air in the environment and the small particles are inhaled more than normal and are drawn deeper into the lungs. Therefore, it should be provided that sport places have acceptable fresh air conditions and it is necessary to do sports in the appropriate time, weather conditions and location to keep the body healthy.

\section{Materials and methods}

\section{Calculation of Air Quality Index}

Air pollutant values are converted to air quality index values by means of the standard formula developed by the United States Environmental Protection Agency (EPA). Air quality index is calculated separately for each pollutant. The pollutant with the highest air quality index is the pollutant of the day in which the air quality is measured. The air quality index value is calculated with the help of equation (1):

$$
\mathrm{I}_{\mathrm{P}}=\frac{\mathrm{I}_{\mathrm{HI}}-\mathrm{I}_{\mathrm{LO}}}{\mathrm{BP}_{\mathrm{HI}}-\mathrm{BP}_{\mathrm{LO}}}\left(\mathrm{C}_{\mathrm{p}}-\mathrm{BP}_{\mathrm{LO}}\right)+\mathrm{I}_{\mathrm{LO}}
$$

Ip: Index for pollutant

Cp: Pollutant rounded cons.

$\mathrm{BH}_{\text {ні: }}$ Break point greater than or equal to $\mathrm{Cp}$

$B P\llcorner O$ : Break point less than or equal to $C p$

$I_{H i}$ IAQ value compatible with $B P_{H i}$

ILO: IAQ value compatible with BPเO

Air pollution increases with the increase inair quality index. The air quality index higher than 100 , indicates that the quality of the air in the environment is not appropriate in terms of health. If the air quality index is higher than 300 , it is possible to deduce that there is a very harmful atmosphere in the environment. According to EPA, air quality values are classified as in Table 1 given below.

\begin{tabular}{|l|l|l|l|}
\hline $\begin{array}{c}\text { Air Quality Index } \\
\text { (AQI) Values }\end{array}$ & $\begin{array}{c}\text { Health } \\
\text { Concern } \\
\text { Levels }\end{array}$ & Color & Mable 1. EPA air quality index classification (Cosgun, 2012). \\
\hline $0-50$ & Good & Green & Air quality is satisfactory and air pollution pose a low risk or none. \\
\hline $51-100$ & Moderate & Yellow & $\begin{array}{l}\text { Air quality is suitable, however, very few people who are } \\
\text { unusually sensitive to air pollution may have moderate health } \\
\text { concerns for some contaminants. }\end{array}$ \\
\hline $101-150$ & Sensitive & Orange & $\begin{array}{l}\text { Health effects might occur for vulnerable groups and generally } \\
\text { the public is unlikely to be affected. }\end{array}$ \\
\hline $151-200$ & Unhealty & Red & $\begin{array}{l}\text { Anyone might start having health issues and there may be serious } \\
\text { health effects for vulnerable groups }\end{array}$ \\
\hline $201-300$ & Harmful & Purple & $\begin{array}{l}\text { Emergency conditions in terms of health can appear. The whole } \\
\text { population is likely affected. }\end{array}$ \\
\hline $301-500$ & Hazardaous & Brown & $\begin{array}{l}\text { Health alarm: Everyone may encounter with relatively more } \\
\text { serious health effects }\end{array}$ \\
\hline
\end{tabular}


Good: Air quality is good if the air quality index is between 0-50.

Moderate: Air quality is accounted as within acceptable limits when the air quality index is between 51 and 100 .

Unhealthy for Vulnerable Groups: When the air quality index is between 101-150, people in the vulnerable group might be adversely affected by the air condition.

Unhealthy: Air quality is unhealthy when the air quality index is between 151-200.

Very Unhealthy: IAQ (Indoor Air Qualıty) implies an alarm level in terms of health for air quality index between 201300.

Hazardous: The air quality has become harmful and the public is negatively affected for the air quality index exceeding 300.

\section{Artificial Intelligence and Fuzzy Logic}

Unlike traditional computational models, artificial intelligence is a vital tool based on mathematical models providing process abilities to the computer and imitating neural the structure and function of the brain. Fuzzy logic, a sub-branch of artificial intelligence, is a mathematical discipline based on fuzzy set theory rather than Aristotle's binary logic. Aristotle's binary logic is based on a decision process such as all-or-nothing, 0-1, yes-no, good-bad. However, fuzzy logic processes the values that fall between these binary values. Fuzzy logic, for example, operates with intermediate values (0.6 - 0.1) instead of less, more, slightly, normal, medium, long, half-line or 0-1 values. In the study, indoor air quality values calculated by using fuzzy logic in MATLAB. Mamdani's Fuzzy logic method was employed in this study.

\section{Mamdani Fuzzy Logic Method}

Mamdani's fuzzy logic method comprises the design of a control system suitable for human thinking. In the method, the outputs are obtained processing pre-defined inputs through the filter governed by the composed rules. In the study, the appropriateness of the evaluation of indoor air quality with artificial intelligence was investigated by analyzing the model created in accordance with the logic structure created with the fuzzy tool in MATLAB.

$\mathrm{CO}_{2}$ and PM10 measurements were performed in Akdeniz University, Technical Sciences with Vocational School (workplaces, laboratories, classrooms), subway (Antray) newly built by Antalya Metropolitan Municipality and in city buses in Antalya, Turkey. The measurements were performed in education periods (including October, November, December in 2010, January, February, March in 2011, October, November, December in 2011 and, Fanuary, February, March in 2012) in a total of 12 months. Moreover, the measurements were made twice a week, especially on cold days, between 07.00-09.30 in the morning, between 11.00-14.00 at noon and between 18.00-20.00 in the evening. Testo535 model hand-held device was used for $\mathrm{CO}_{2}$ measurements. Testo 535 model device can be seen in Figure 2 given below.

Figure 2. Testo 535 model device used in $\mathrm{CO}_{2}$ measurements (Cosgun, 2012; Web site-4).
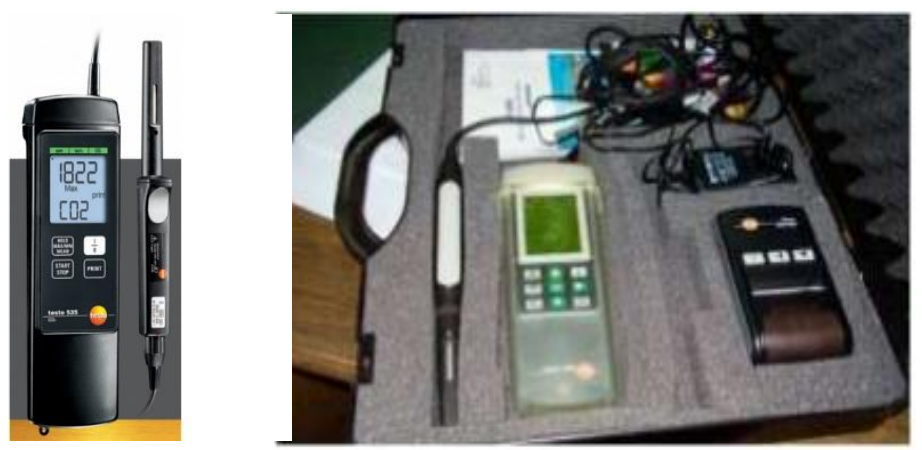

In the $\mathrm{CO}_{2}$ measurements, once the Testo535 model device was turned on, the probe connected to the device is held on the environment manually and the device, which operates in carbon dioxide mode, automatically collects data within 3-4 seconds. In carbon dioxide measurements, the device automatically provides the minimum, maximum and average values of the carbon dioxide value. The device stores data in its embedded memory instantly, the outputs of the measurement were also printed out by means of remote sensing printer.

In dust particle measurements, measurements were made with the Fluke 983 dust counter device. The device has the ability to measure six channels of the particle distribution $\left(\mathrm{PM}_{0.3}, \mathrm{PM}_{0.5}, \mathrm{PM}_{1.0}, \mathrm{PM}_{2.0}, \mathrm{PM}_{5.0}, \mathrm{PM}_{10}\right)$ temperature and humidity simultaneously. The device is also able to visualize data and it can display particles with the dimensions up to $0,3 \mu \mathrm{m}$. It also has the ability to store 5000 records of location in addition to some special properties such as selectable 
sampling time, count data, a programmable delay, date, time, count, relative humidity, temperature, sample volumes, alarms. Recorded data can be transferred to a computer owing to the software. The compact, independent enclosure allows one-handed operation. The easy-to-use user interface is always ready for operation, without any fluid filling. Backlight LCD is available for use in any light position. An 8-hour rechargeable battery is used in the system. Fluke 983 can also detect size distributions of particles spreading by air, or trace a particle to its source. Fluke 983 type dust counter device can be seen in Figure 3 given below.

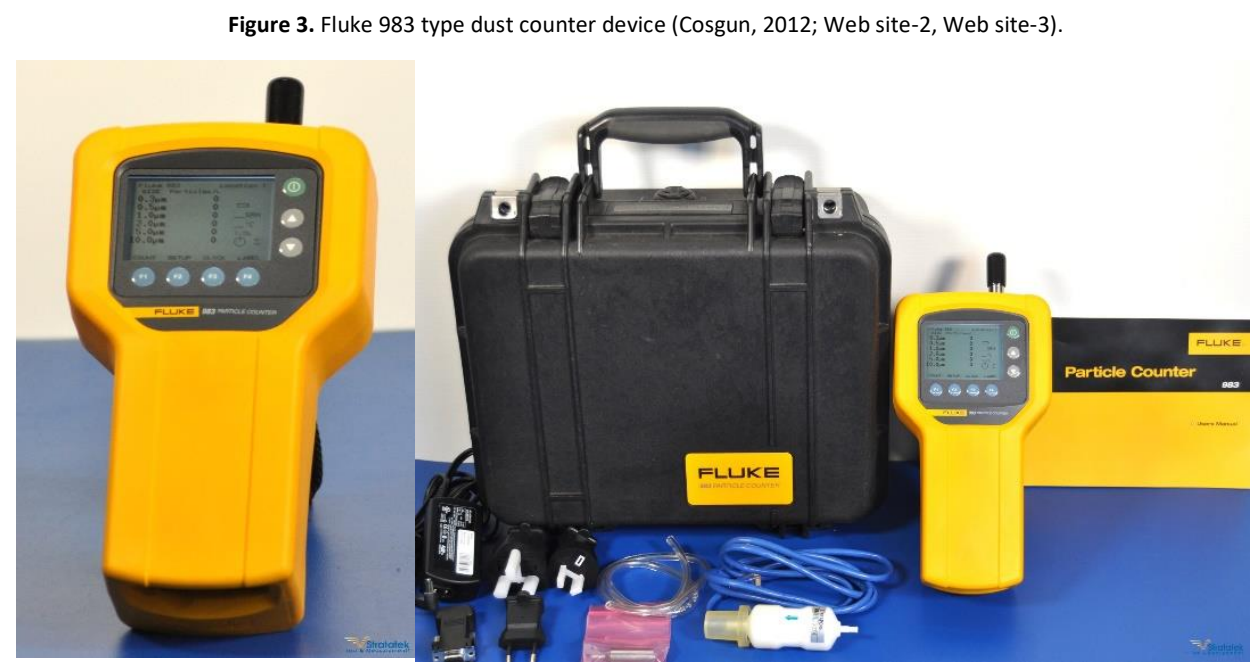

The device is adjusted for a specific particle size value in the volume where the measurements for $\mathrm{PM}_{10}$ are carried out (i.e. for dust particles with a diameter of $10 \mu \mathrm{m}$ ) and the measurement results are obtained by activating the reading mode. The measurement values were in the interested volumes instantly and, the results were transferred to the computer to evaluate extensively. Measurement results were also presented in a doctoral dissertation which was titled "Investigation and modeling of indoor air quality for different environments in Antalya province" and submitted to the Institute of Science in Balıkesir University (Cosgun, 2012).

A Mamdani type model consisting of two inputs and one output was prepared for fuzzy logic simulation in this study. The PM10 and CO2 data exemplified in Table 2 were used as input data (Web site-4). IAQ values determined by EPA are used as output data. FIS editor, which was utilized in Fuzzy Logic Toolbox and edited according to the parameters using the MATLAB 2018 program, is shown in Figure 4 given below.

Table 2. Input data based on actual measurement results (Cosgun, 2012). (All of the data is not shared here, the shared table is an example containing some of the data used).

\begin{tabular}{|c|c|c|c|c|c|}
\hline $\begin{array}{c}\text { Akd.Ünv.Tbmyo } \\
\text { October workshop } \\
\text { values }\end{array}$ & $\begin{array}{c}\text { Akd.Ün. Tbmyo } \\
\text { November workshop } \\
\text { values }\end{array}$ & $\begin{array}{c}\text { A } \\
\text { Akd.Unv. Tbmyo } \\
\text { Decer workshop } \\
\text { values }\end{array}$ \\
\hline PM10 & CO2 & PM10 & CO2 & PM10 & CO2 \\
\hline 400 & 28 & 410 & 27 & 462 & 24 \\
\hline 384 & 24 & 388 & 24 & 467 & 27 \\
\hline 386 & 21 & 389 & 25 & 469 & 29 \\
\hline 371 & 20 & 370 & 26 & 460 & 32 \\
\hline 317 & 18 & 310 & 28 & 452 & 31 \\
\hline 319 & 17 & 310 & 24 & 463 & 31 \\
\hline 384 & 30 & 378 & 19 & 469 & 35 \\
\hline 438 & 14 & 430 & 24 & 458 & 34 \\
\hline 421 & 13 & 418 & 22 & 459 & 38 \\
\hline 413 & 15 & 419 & 24 & 475 & 37 \\
\hline 316 & 25 & 314 & 21 & 471 & 36 \\
\hline 319 & 24 & 315 & 23 & 478 & 34 \\
\hline
\end{tabular}


Figure 4. FIS editor tool created in MATLAB for air quality.

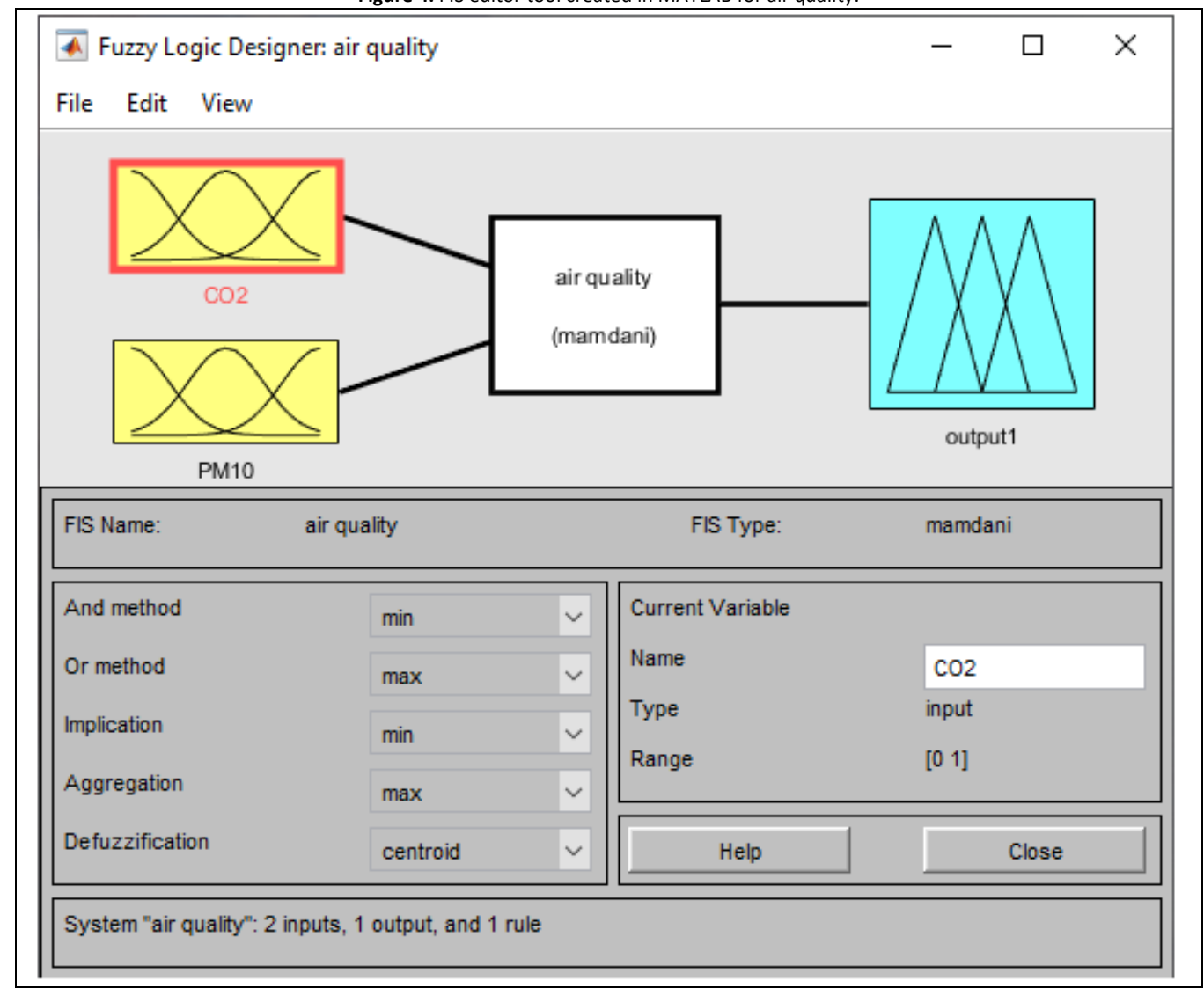

$\mathrm{CO}_{2}$ and $\mathrm{PM} 10$ variables used as input data and membership function values created for IAQ output variable are shown in Figures 5 to 7, respectively.

Figure 5. Membership functions value for $\mathrm{CO}_{2}$

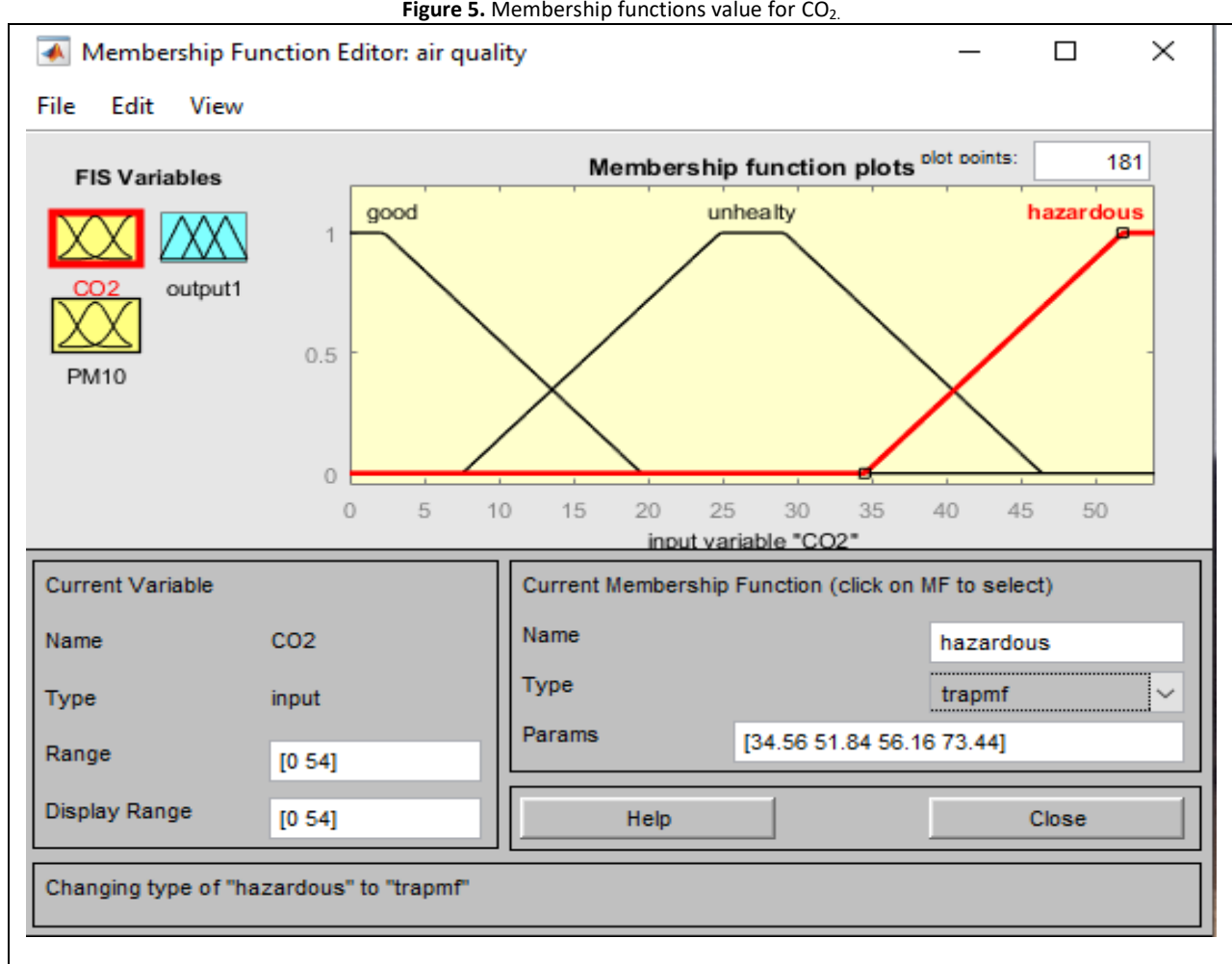


Figure 6. Membership functions value for $\mathrm{PM}_{1}$

Membership Function Editor: air quality

File Edit View

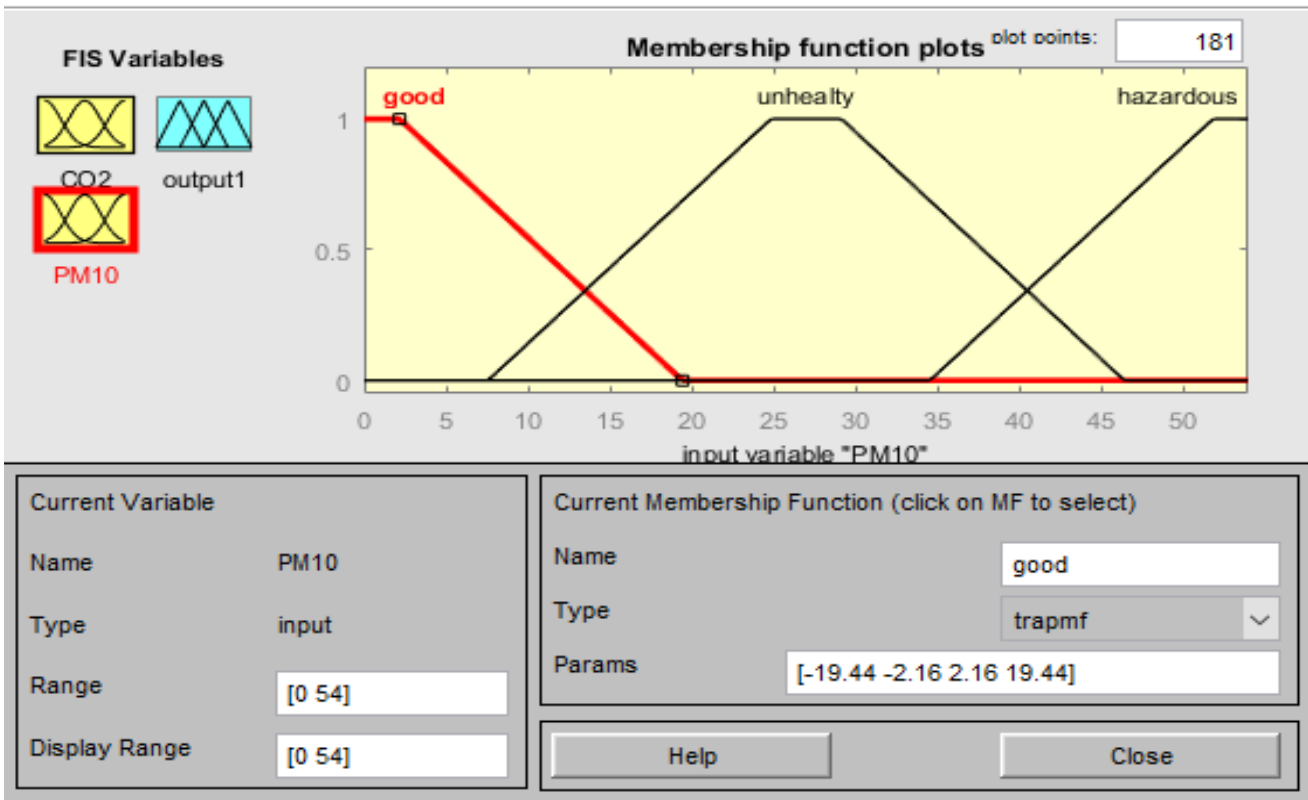

Changing type of "hazardous" to "trapmf"

Figure 7. Membership functions value for air quality.

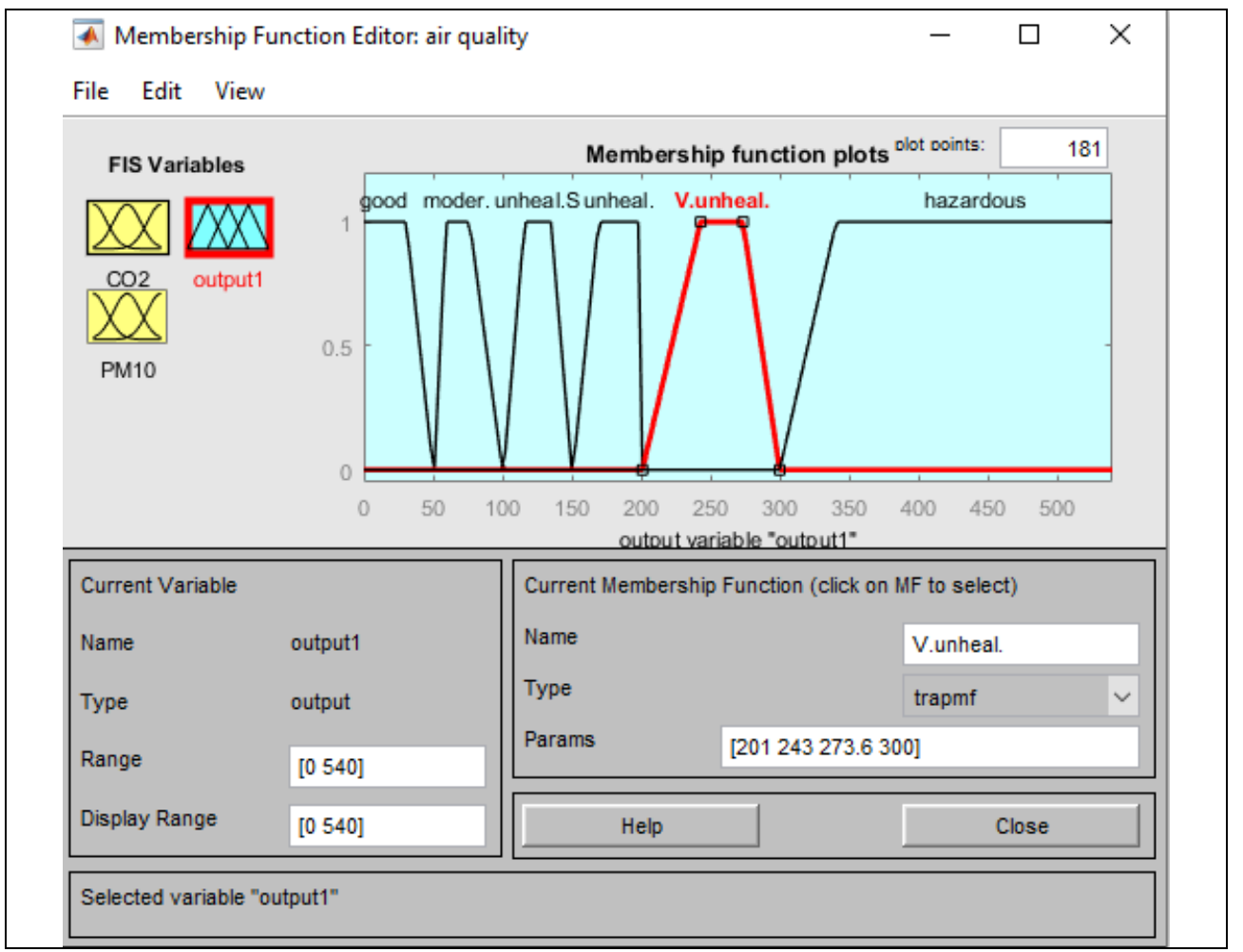

The rules for control system determining the input-output relationships are shown in Figure 8 . The graphic interface suitable for the input and output parameters is shown in Figure 9. 


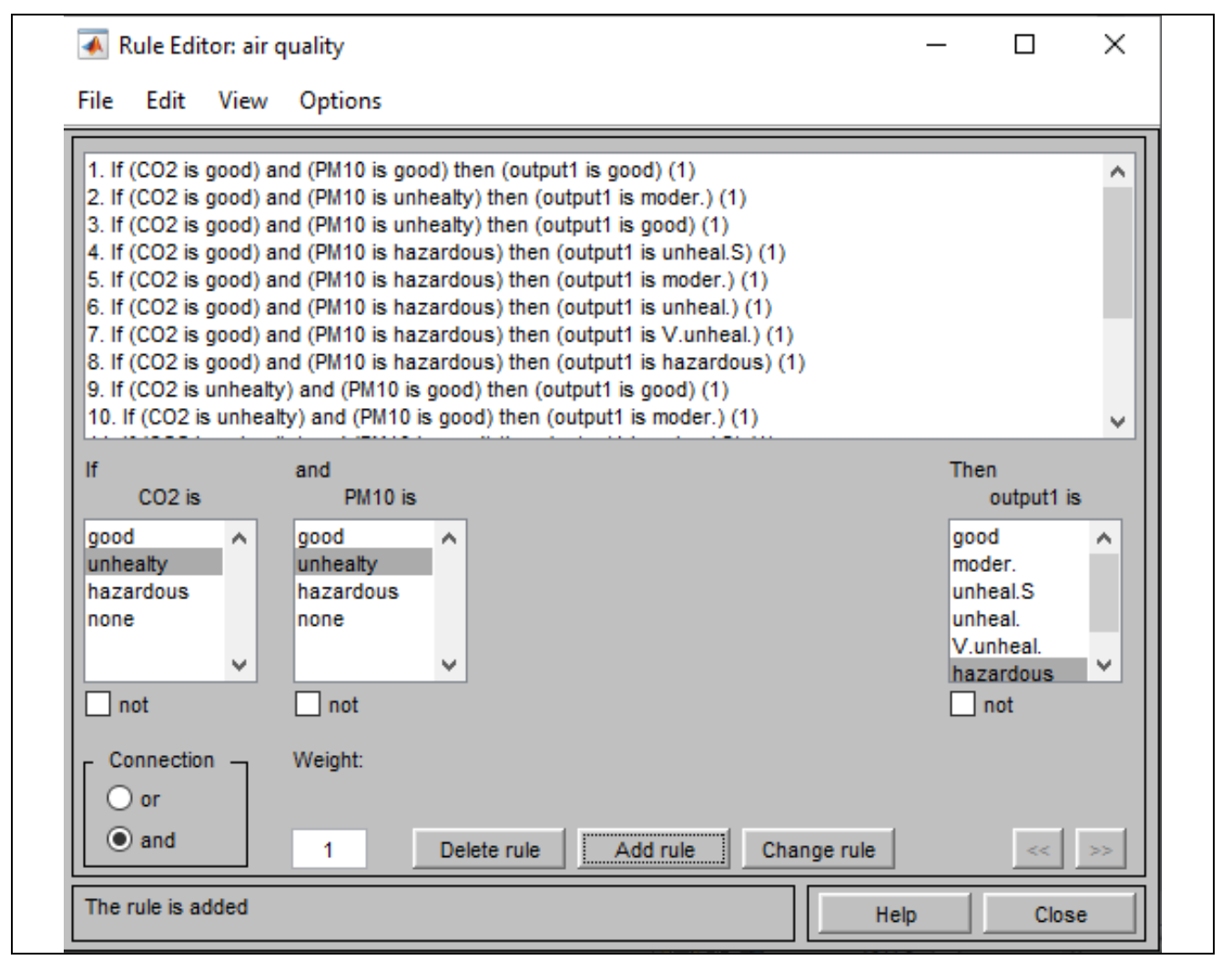

Figure 9. The graphic interface for the input and output parameters.

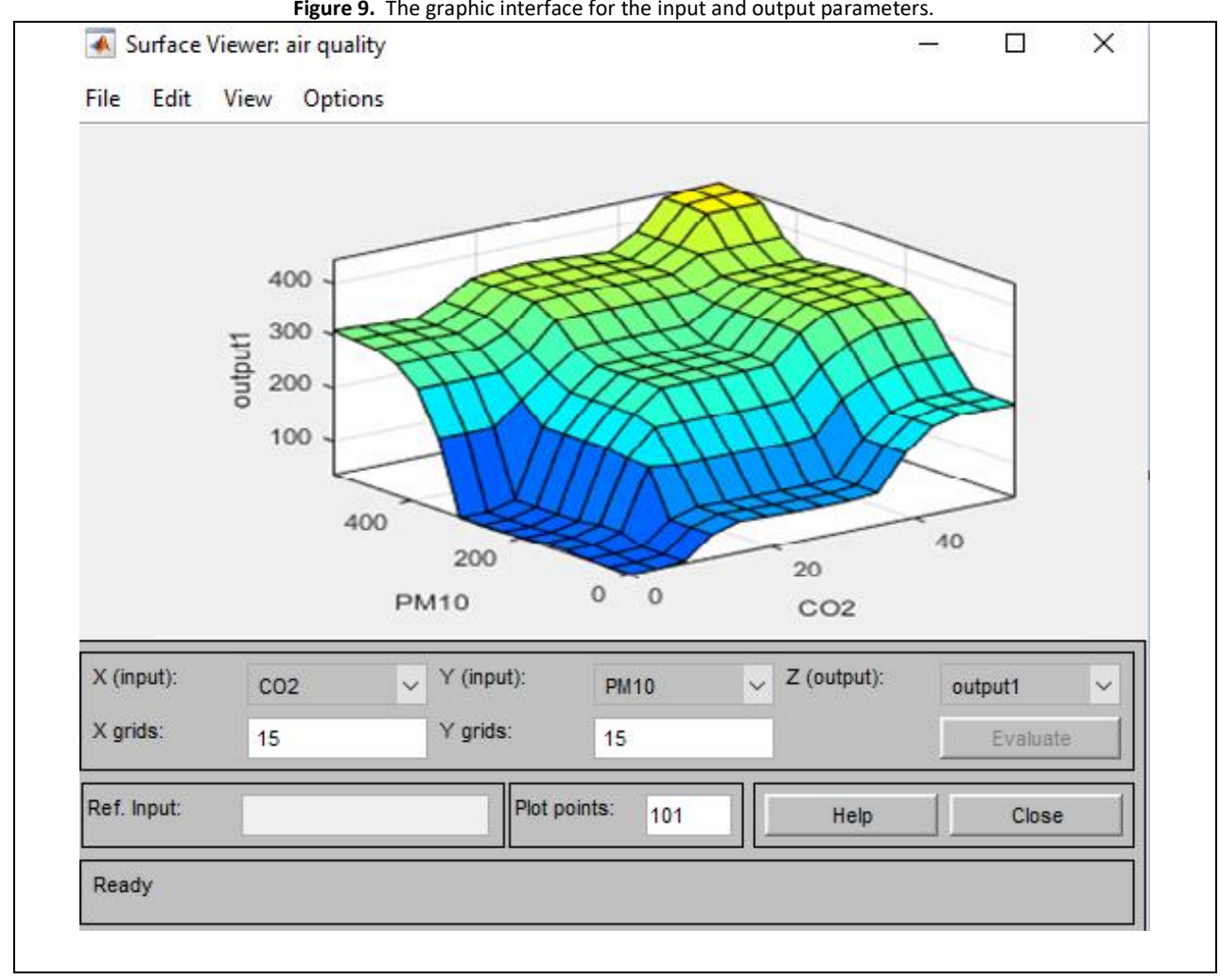

The interface belongs to the Defuzzycifation process, which was designed depending upon all stages of Fuzzycifation in the fuzzy logic model created in this study, are obtained as shown in Figure 10. 


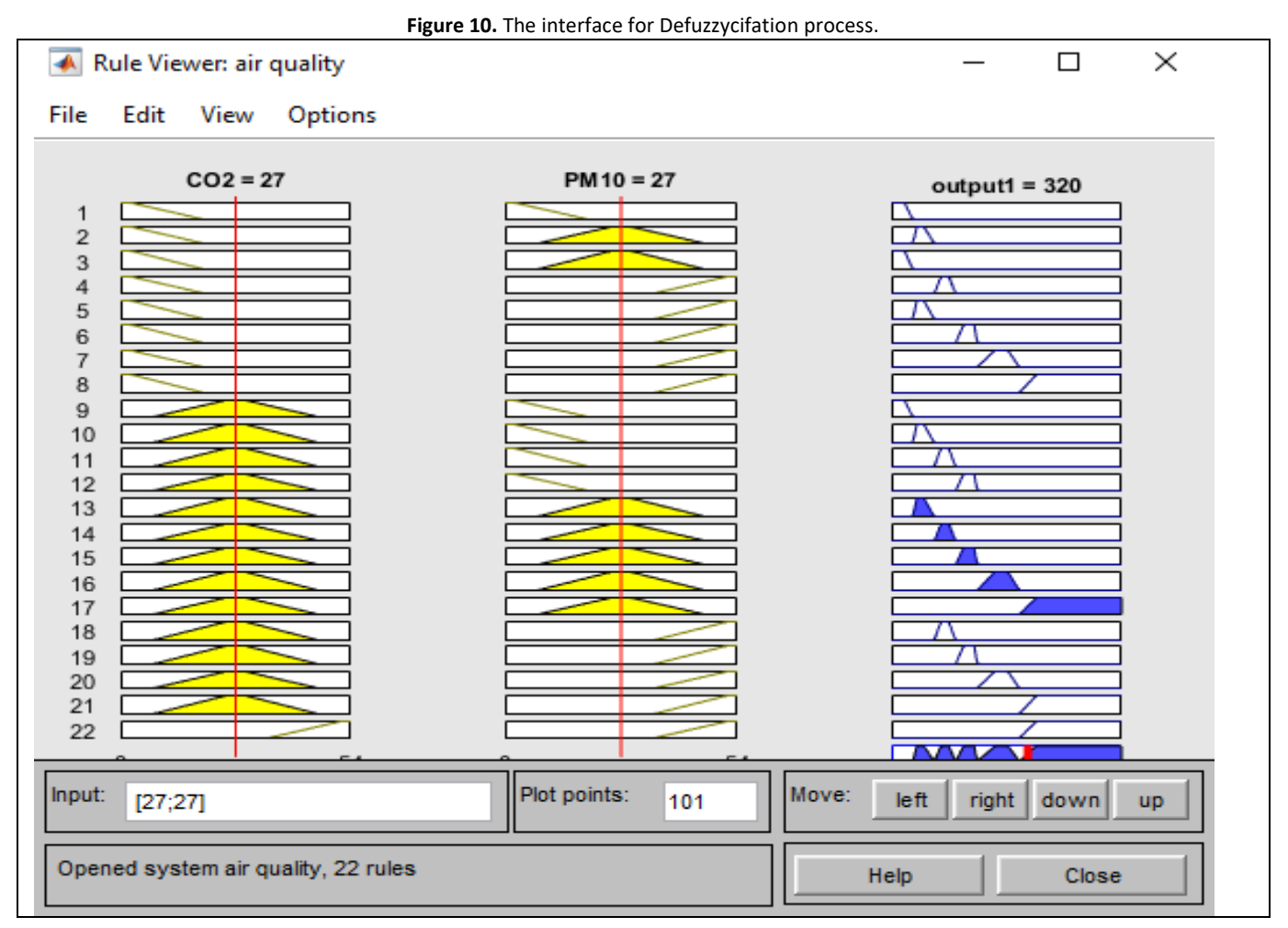

Analyzing the data presented in the above-referred doctoral thesis, it was found that $\mathrm{CO}_{2}$ measurement values taken from the regions close to the windows ( $\mathrm{I} . \mathrm{CO}_{2}$ values) and the measurements taken from middle regions of the volume (II. $\mathrm{CO}_{2}$ values) were much higher than $1000 \mathrm{ppm}$ value given in ASHRAE standards. However, it was also determined that 3500 ppm, which is the limit value according to Canadian standards, was not exceeded in all $\mathrm{CO}_{2}$ measurements. In indoor air quality measurements performed in the winter months, it was revealed that the $\mathrm{CO}_{2}$ value in the classrooms (Workshop, laboratory, classroom) was high since the classrooms were kept closed and there was no ventilation system in areas in which the measurements were made (there was no central air conditioning system). In order to reduce the $\mathrm{CO}_{2}$ values, the ventilation system can be installed in the classrooms where the measurement is made and, by doing so, the $\mathrm{CO}_{2}$ level can be kept below the standard values. Therefore, it is recommended to install $\mathrm{CO}_{2}$ sensors in the classrooms. In indoor environment, air particles were found to have a mean PM10 value of $75,79 \mu \mathrm{g} / \mathrm{m}^{3} \mathrm{According}$ to the PM10 measurement result, it was also determined that the mean of measurement results was greater than the limit value specified in the ASHRAE standard $\left(\mathrm{PM} 10<75 \mu \mathrm{g} / \mathrm{m}^{3}\right)$. Therefore, the existing content exceeded the given standard value. Considering that mean of $\mathrm{PM}_{10}$ measurement values is $75,79 \mu \mathrm{g} / \mathrm{m}^{3}$, it is lower than the limit value of Chinese Standard $\left(\mathrm{PM}_{10}<150 \mathrm{\mu g} / \mathrm{m}^{3}\right.$ ), higher than the limit value defined by WHO (World Health Organization) standards (PM 10 $\left.<20 \mu \mathrm{g} / \mathrm{m}^{3}\right)$ and higher than the limit value of British Standard $\left(\mathrm{PM}_{10}<50 \mu \mathrm{g} / \mathrm{m}^{3}\right)$. On the other hand, Honkong standard value PM10 <180 $\mathrm{mg} / \mathrm{m}^{3}$ (2nd level) limit value, PM10 average measurement value was determined to be lower than $75.79 \mu \mathrm{g} / \mathrm{m}^{3}$ in this study.

As a result of the evaluation of the indoor air quality index in public living areas with the EPA air quality index classification instead of comparing indoor air quality measurement results with standard values, new approaches can be introduced by finding the "health concern" values of indoor air.

According to the EPA air quality index classification and the graph in Figure 9, it was concluded that the air quality index is good, the air quality is satisfactory and air pollution shows little or no risk since the air quality index given in green is between 0-50. As it is shown in the same graph, the air quality index values for the yellow-colored regions are between 51-100 and it means that air quality index reached the medium level and air quality is appropriate. However, it might bring about moderate health concerns in terms of some pollutants for few people who are unusually sensitive to air pollution. 
One of the most critical problems emerging in system design is that the mathematical model of the system under the investigation is difficult and intricated. In this study, it was observed that the parameter values can be examined using a few parameters throughout interactive methods for different conditions of network models without any prerequisites in fuzzy logic, unlike classical statistical and functional modeling techniques.

Employing Fuzzy Logic, the control process is created in a simpler way with the help of linguistic variables without the need for a mathematical model of the system. Generalization capability in fuzzy logic creates the model with the highest efficacy. However, the biggest problem is that the system performance can be increased by a trial-and-error method to create parameters of the system to be investigated when the expert experiences are not utilized and, this process is time-consuming. In this study, the same problem was encountered and many methods were tried to improve performance criteria. It was determined that much better results can be obtained including the other pollutant parameters in the model in addition to expanding database in terms of quantity and quality.

In this study, control design was implemented for indoor air quality and simulations were performed in the Fuzzy Logic Toolbox of Matlab to observe the system results.

The effects of indoor air quality on health draw attention in the progress of time. It can be suggested that researches using different analysis methods can be encouraged in the graduate level.

As a result of researches in the literature, indoor air quality studies can be conducted for gyms which are the collective work areas and it must be ensured that the employees, who are working in demolition work for urban transformation in Turkey, are not exposed to dirty and dusty air. The most important issue, in that case, is to determine the exposure values in terms of indoor air quality as long as the workers using the construction equipment in the demolitions of the building (the interior space of the vehicle is considered as an indoor environment) and to make improvements by comparing with the standard values regarding work safety precautions presented in regulations with the number of 6331. Thus, the number of patients with lung cancer can be reduced especially in these kinds of places which are unhealthy in terms of air quality and, accordingly, financial losses such as hospital expenses can be avoided.

By finding indoor air quality index values in institutions such as public hospitals, shopping centers, schools, universities, indoor air quality maps can be created by assessing these indoor air quality index values and Geographical information systems (GIS) data.

References

Altın, M. \& Taşdemir, ş. (2018). Occupational health and safety. Textbook, 241, ISBN:978-605-9831-94-9

Ashrae (2003). ASHRAE Handbook CD, 2001 Fundamentals. Chapter 9: Indoor Environmental Health, Atlanta, USA.

Ashrae (2007). Standard 62.1-2007 user's manual, Atlanta: American Society of Heating, Refrigerating and Air-Conditioning Engineers.).

Bos, I., Boever D, P., Panis.L, I. \& Meeusen, R. (2014). Physical Activity, Air Pollution And The Brain. Sports Med, 44:1505-1518, DOI 10.1007/s40279014-0222-6.

Bulut, H. (2012). Analysis of CO2 content in terms of ventilation and indoor air quality. Proceedings of Plumbing Engineering Congress, 128(1), 61-70.

Cavkaytar, Ö., Soyer,Ö.,U. \& Şekerel, B. E. (2013). Air Pollution based Health Issues in Turkey, Air Pollution Researchs Journal 2, 105 - 111, 17.11.2013

Ceylan, A. (2011). Negative Effects of Air Conditioning Systems on Internal Air Quality, Master thesis Tezi, Yildiz Technical University, Institute of Science, ìstanbul.

Coskun C. \& Oktay, Z. (2020). Carbon footprint prediction of vehicle usage in Turkey, Greenhouse gases: Sicience and Technology. 736-758, 23.04.2020. https://doi.org/10.1002/ghg.1980

Coskun C. (2019). A time-varying carbon intensity approach for demand-side management strategies with respect to CO2 emission reduction in the electricity grid. International Journal of Global Warming (IJGW), 19, 1/2, 10.1504 / IJGW.2019.101768

Çoşgun, A. (2012). Investigation and modeling of indoor air quality in different environments in Antalya province, Balıkesir University Institute of Science, Doctoral Dissertation.

Çilingiroğlu, S. (2010). Indoor air quality, Installation Engineering Journal, 115, 01-02.2010, http://www1.mmo.org.tr/resimler/dosya_ekler/7f2a4ea3bedd425_ek.pdf?dergi=966 (Accessed on 16.12.2019)

Eres, B. (2019). Investigation of the Relationship of Hvac Systems with User Health in Terms of Thermal Comfort and Indoor Air Quality" Master thesis, Fatih Sultan Mehmet University Lisansüstü Institute of Education, Department of Architecture. 
Gómez-Rubiera, E. L., Sánchez-Torija, J.G. \& Frutos, C.B. (2019). Zero cost conditioning techniques to improve the indoor environment of schoo buildings. Revista de la Construccion, 18, 3, 525-535, https://doi.org/10.7764/RDLC.18.3.525

Oliveira, M., Slezakova K., Matos C. D., Pereira M. C. \& Morais S. (2016). Assessment of polycyclic aromatic hydrocarbons in indoor andoutdoor air of preschool environments (3-5 years old children). Environmental Pollution, 208, 382-394.

Kaplan, G. G., Tanyingoh, D., Dixon, E., Markey J, Wheeler, A., J., Mayers R., P., M, Bertazzon, S., Saini, V., Madsen, K., Ghosh, S. \& Villeneu J.P. (2013) Ambient Ozone Concentrations and the Risk of Perforated and Nonperforated Appendicitis: A Multicity Case-Crossover Study. Environmental Health Perspectives, 121,8, https://ehp.niehs.nih.gov/doi/full/10.1289/ehp.1206085 (Accessed on 17.12.2019).

Knudsen, H. \& Rasmussen, N. (2011). Particulate Matter: Sources, Emission Rates and Health Effects (Environmental Science, Engineering and Technology), Nova Science Pub. Inc., New York, N.Y.

Köksal, Y. (2011) "Improvement of Air Quality in Closed Areas" 625-645, V. National Installation Engineering Congress and Exhibition 2011. http://mmoteskon.org/wp-content/uploads/2014/12/2001-39.pdf. (Accessed on 16.12.2019).

Kuşcu, E. (2018). The Effect of Air Quality in Classes on Learning. Master Thesis, Kastamonu Institute of Social Sciences, 2018, Kastamonu

Lakestanı, S., Vaizoğlu,S., A., Doğan, B., G., Şekerel, B. \& Güllü, G. (2017). Investigation on relationship between indoor air quality and respiratory Diseases in infants. VII. National Air Pollution and Control Symposium Akdeniz University, Faculty of Engineering, Department of Environmental Engineering 1-3 Kasım 2017, Antalya.

Oral, Z. A. \& Arısoy, A. (2015). Indoor air quality in shopping malls, 12th Congress of Plumbing Engineers, 1-9, 08-11 April 2015, TESKON 2015, İzmir. Turkey

Shaughnessy, U. H. (2015). The effects of internal environment quality on student health and learning in European and USA schools. 12th Congress of Plumbing Engineers, 1-9, 08-11 April 2015, TESKON 2015, İzmir,Turkey

Tül, H. \& Saraç, K. (2015). Evaluation of particulate matter data in Turkey, Master Thesis, Ataturk University, Institute of Science.

Web site-1 https://www.memurlar.net/haber/868130/ air-pollution-increases-the-risk-of-lung-cancer-.html (Accessed on 20.11.2019).

Web site-2 https://static.wixstatic.com/media/e09521_7879d56a90554c869016ac 38c 2a mv2.jpg/v1/fill/w_1516,h_2488,al_c,q_85/e09521_7879d56a90554c869016 ac38cf39d52a mv2.jpg(Last Access Date 15.11.2020).

Web site-3 https://static.wixstatic.com/media/e09521_e7955461350645adb028c662f51d1b9 c mv2.jpg/v1/fill/w_3848,h_2684,al_c,q_85/e09521_e7955461350645adb028c662f51d1b9c mv2.jpg (Last Access Date 15.11.2020).

Web site-4 https://highmed.vteximg.com.br/arquivos/ids/155893-1000-1000/TESTO 535.png ?v=636054065494000000 (Last Access Date 15.11.2020). 